\title{
Developing a Learning Progression of Buoyancy to Model Conceptual Change: \\ A Latent Class and Rule Space Model Analysis
}

\begin{abstract}
We applied latent class analysis and the rule space model to verify the cumulative characteristic of conceptual change by developing a learning progression for buoyancy. For this study, we first abstracted seven attributes of buoyancy and then developed a hypothesized learning progression for buoyancy. A 14-item buoyancy instrument was administered to $10898^{\text {th }}$ grade students to verify and refine the learning progression. The results suggest four levels of progression during conceptual change when $8^{\text {th }}$ grade students understand buoyancy. Students at level 0 can only master Density. When students progress to level 1, they can grasp Direction, Identification, Submerged volume and Relative density on the basis of the prior level. Then, students gradually master Archimedes' theory as they reach level 2. The most advanced students can further grasp Relation with motion and arrive at level 3. In addition, this 4-level learning progression can be accounted for by the QualitativeQuantitative-Integrative explanatory model.
\end{abstract}

Keywords: buoyancy, learning progression, Latent Class Analysis, Rule Space Model, conceptual change

\section{Introduction}

The conceptual change amongst physics students is a result of the learning process (Posner et al. 1982). To uncover how the conceptual change occurs has been a great challenge for science educators since the 1980s. Based on the studies of Piaget $(1930,1969)$ of how students develop scientific explanations, multiple assumptions were proposed to model this complex cognitive evolution process. The core divergence of these assumptions lies in how the knowledge status progresses from novice-like to expert-like. Among the many studies on this topic, diSessa (2013) and diSessa et al.'s (2004) contributions stand out. Unlike other assumptions such as "theory theories", which assume that the understanding of the physical world among students is a spontaneous process marked by equal pace 
(McCloskey 1983a, 1983b), diSessa (1988) asserted that concepts were fragmented initially but eventually became integrated as learning occurred. The conceptual change was marked by the integration of more and more pieces of knowledge into a coherent and structured entity (diSessa 2013; diSessa et al. 2004). For example, to understand Ohm's law, one first abstracts a series of key attributes such as "resistance" from a common experience_-"Pushing a box with variable effort on different surfaces", and then gradually integrates them to formulate a more sophisticated understanding of Ohm's law (diSessa 1988). The accumulation accompanied with an integration of these kinds of attributes indicates conceptual change (diSessa 2007, 2013).

Besides the studies of diSessa and his colleagues, other prevalent theories toward conceptual change also indicated this accumulative characteristic. For example, Norman and Rumelhart (1981) discerned accretion as one of three main categories of conceptual change. They contended that student understanding of certain concepts changed as knowledge accumulated. The difference to diSessa was that they did not explicitly point out that knowledge was fragmented. She (2002) supported this point of view and stated conceptual change as a "gradual accretional phenomenon rather than a Kuhnian scientific revolution" (p. 982). Another influential theory asserted that students embraced an explanatory framework primitively and then reconstructed the framework, which also acknowledged the accumulative characteristic (Vosniadou 1994; Vosniadou and Brewer 1992; Vosniadou et al. 1987). Chi (1992) and Chi et al. (1994; 2003) differentiated two kinds of conceptual change — the Compatibility Hypothesis and the Incompatibility Hypothesis. Specifically, the Incompatibility Hypothesis assumes that the existence of a mismatch between students' naïve conceptions and the ontological category to which a science concept truly belongs results in students' difficulty in learning this scientific concept. The Compatibility Hypothesis predicts that conceptions should be relatively 
easy to learn if students' naïve conceptions are compatible with the scientific conceptions. In addition, this conceptual change was accompanied with the accumulation of knowledge as well (Chi et al. 1994). In sum, while "some major debates" (Taber 2010) remain in the research field of conceptual change, nevertheless, the cumulative characteristic of the cognitive process draws upon a consensus among the main conceptual change theories in science education.

Despite this, studies on conceptual change seldom capture the cumulative process to uncover the progress patterns of conceptual change empirically. We surveyed four review studies discussing conceptual change that cover the literature ranging from 1987 to 2016 (Guzzetti 1993; Mills et al. 2016; Soto Lombana et al. 2005; Taber 2010), among which one only focused on instructional issues and one only focused on qualitative research on conceptual change. A systematic analysis of the relevant studies suggested that researchers focused on modelling the process of conceptual change mainly before the year of 2000, and Soto Lombana and his colleagues' (2005) review confirmed our claim, since they found that $76.9 \%$ of these kinds of studies appeared between 1996 and 2000. Excluding the two reviews, we traced the remaining two review studies and found that they documented 26 studies that focused on the modelling of conceptual change (Soto Lombana et al. 2005; Taber 2010). In-depth inspection indicated that most of them were qualitative or theoretical studies, and no study empirically modeled the cumulative property of conceptual change. Hence, no study considered in these reviews modeled the cumulative property of conceptual change in physics. Drawing upon these research gaps, we conducted a quantitative study by collecting $10898^{\text {th }}$ grade students' data to model the cumulative characteristic of conceptual change in physics learning, specifically focusing on the concept of buoyancy. 
To achieve the goal of modelling the cumulative characteristic of conceptual change, we developed a learning progression—used to model "increasingly sophisticated ways of thinking about or understanding a topic" (National Research Council 2007)—for the understanding of buoyancy. We first abstracted seven attributes of the concept of buoyancy and theoretically developed a hypothesized 5level learning progression by accumulating more attributes to higher levels. To empirically validate the learning progression, we employed Latent Class Analysis (LCA) and the Rule Space Model (RSM). Two research questions lead this study:

(1) Can the cumulative characteristic of conceptual change be modelled by a learning progression?

(2) If it can, what patterns do students show in the process of conceptual change in terms of understanding buoyancy?

In the following we give an overview of the concept of a learning progression and then theoretically develop a hypothesized learning progression for buoyancy. Last, we describe how LCA and the RSM will be used in validating and modifying the learning progression.

\subsection{Learning progression}

The idea of learning progressions stems from a much older idea—conceptual change (Wilson 2009). However, the studies on learning progression highlight both the developmental and cognitive features, whereas the studies on conceptual change were more concerned about cognitive features. Specifically, learning progressions would inform both curriculum and assessment development (Songer et al. 2009). For curriculum development, learning progressions provide evidence for the sequences of curricular units. For assessment development, learning progressions-based assessments not only describe students' present level but also point out their learning path. Therefore, a learning progression carries forward the objective of the studies in terms of conceptual change. Since the first published 
learning progression by the National Research Council (NRC; Wilson and Bertenthal 2005), many studies have been conducted to explore students' progression in understanding a specific body of knowledge such as energy (Neumann et al. 2013), force and motion (Alonzo and Steedle 2009) and matter (Stevens et al. 2010; Talanquer 2009). The potential of a learning progression in mapping students' progression in conceptual change had been empirically validated. These empirical studies usually focused on a big idea in science, covering a large time span. However, learning progressions with a large time span are difficult for teachers to use in the classroom (Alonzo and Gearhart 2006). Therefore, short time span learning progressions that focus on modelling students' understanding of a specific concept such as buoyancy are valuable, especially from a classroom perspective.

Developing a learning progression starts by defining the upper anchor, lower anchor and the "messy middle" — that is, to formulate a hypothesized learning progression theoretically (Stevens et al. 2010). The second step is to empirically validate and to refine the hypothesized learning progression. Neumann and his colleagues (2013) summarized two approaches to validate a learning progression. First, by inserting measurement tools into the instructional interventions, the researchers were able to capture the students' conceptual change at different time-points. In order to pursue such an objective, the researchers have to develop different measurement tools according to the interventions. However, it is difficult to establish high fidelity between the intervention and the assessment tool and therefore this approach is seldom used in the literature. The second approach is to develop a measurement tool focusing on the whole learning progression. The items in the measurement tool should be anchored to specific levels of the learning progression. Then, researchers can employ for example a Wright map to map students' understanding to the specific levels (Wilson 2005). Any incompatibility of the expected 
item difficulty and the empirical difficulty would suggest revision and more rounds of validations. To date, most learning progressions followed the latter approach, as does the current study.

Before following the second approach mentioned above, we should note its limitation. It is not a method that directly tracks the progression of a student in understanding a scientific concept within a time span. Instead, it is a cross-sectional study that groups students into different levels of understanding but employs the same time frame (Neumann et al. 2013). However, this limitation was broadly accepted in the prior studies in terms of developing learning progressions (Alonzo and Steedle 2009; Chen et al. 2016). The advantages of the method outweigh the limitations, since the approach allows researchers to employ a large sample size to statistically explore the change or progression in the understanding of a scientific concept. Drawing upon this advantage, we followed the second approach.

\subsection{Theoretically Developing a Hypothesized Learning Progression of Buoyancy}

The traditional approach to developing a learning progression usually refers to the curriculum standards to determine the upper anchor, whereas a literature review in terms of students' misconceptions is done to set the messy middle and the lower anchor (Duschl et al. 2007; Neumann et al. 2013; Smith et al. 2006; Stevens et al., 2010). Such an approach meets the general requirement of a learning progression development, but it does not in detail describe the steps in the learning progression. For instance, Stevens and his colleagues (2010) developed a learning progression to model the nature of matter, in which they declared "building conceptual understanding involves taking newly introduced information and connecting it to existing knowledge as the student builds an organized and integrated structure" (p. 689). However, they followed the before-mentioned traditional approach to develop the hypothesized learning progression. This is difficult if the intent is to identify the 
cumulative characteristic, especially when some students are outliers. Compared to the traditional approach, our method was more straightforward. We first abstracted seven attributes and then analysed their hierarchical relationship. A hypothesized learning progression was proposed by accumulating the attributes students mastered.

Before proceeding to do other work, we want to revisit the idea of physical concept and to consider how these come into being. According to Piaget's $(1930,1969)$ long-term work, it has been a commonplace belief that concepts were formalized especially when people try to explain the reason and detect causality for some naturally occurring phenomena. diSessa $(1988,1993)$ used the agentpatient relation to explain and predict a particular circumstance. An agent means the impetus or a kind of activity which produces some sort of qualitative relationship. A patient is an object in whose behaviour the effect of the agent's action is at issue. For example, when people conceptualize force-a kind of interaction - they must put the concept in a familiar situation like "I pull the stone, and it moves". In this example, $I$ is the animate agent and the stone is the patient, whereas pull is the legitimized interaction and move is the causal result. Without the agency, force is difficult to conceptualize. In this sense, conceptualization of a physical concept involves specific agency, or might also require the specific circumstance. This claim is essential for classroom students to develop their initial fragmented knowledge of buoyancy and eventually integrate it into a scientific concept. It will be difficult for a student to formalize buoyancy without agencies such as objects and liquid, and only thanks to a causal circumstance such as sinking or floating can they construct the concept. Applying these arguments to our own study, we set our physical concept "buoyancy" in a causal circumstance with typical agencies_ - objects sink and float in liquid or gas (Şahin and Çepni 2012). We then probed how the understanding of buoyancy progresses in students. 


\subsubsection{Abstract the attributes of buoyancy}

The attributes of buoyancy were determined from the student-learning perspective. Therefore, we considered both the nature of buoyancy and the factors that influenced students' understanding of buoyancy. Two important factors were recognized when we abstracted the attributes - - the hierarchical property and misconceptions (Joung 2009; Şahin and Çepni 2012; She 2002, 2005). The hierarchical property helps to recognize the relevant sub-concepts of buoyancy, whereas the misconceptions help to identify the critical issues that influence students' understanding. She (2002) first recognized buoyancy as a hierarchical concept, which subsumed underlying concepts such as density, submerged volume and displaced liquid. In her empirical study, She (2002) concluded that the hierarchical property was a crucial factor influencing students' conceptual change. Drawing upon this hierarchical property, three attributes of buoyancy were extracted: 1) the water particles exert forces on every side of an object, of which the vertical net force is the buoyancy; 2) the buoyancy is equal to the weight of the fluid displaced by the object; 3) a number of sub-concepts are related to floating and sinking such as the density of the object, the density of the liquid, and the submerged volume.

Yin $(2005)$ and Yin et al. $(2008 ; 2008,2014)$ recognized four sets of sub-concepts of buoyancymass or volume, mass and volume, object density and relative density. These four sets of sub-concepts form a complex four-level hierarchical structure. They argued that students' understanding of buoyancy would follow such a trajectory — from a lower level to a higher level, which will also indicate the sequence of the attributes in the next part.

Besides the hierarchical property, we also recognized misconceptions as another main factor when abstracting the attributes of buoyancy. Misconceptions among students are common before they receive formal instruction (National Research Council 2001). Since buoyancy is one of the most challenging 
concepts for students, many studies have examined misconceptions of buoyancy (Havu-Nuutinen 2005; Loverude et al. 2003; Maclin et al. 1997; She 2002, 2005; Smith et al. 1985; Yin et al. 2008). For example, Yin and her colleagues $(2008 ; 2008,2014)$ summarized ten misconceptions around the phenomenon of sinking and floating, like the misconceptions that heavy objects and objects of a large size would sink.

We did a broader review and found some additional misconceptions about buoyancy. Ünal and Costu (2005) examined 120 eighth-grade students' understanding of buoyancy in terms of sinking and floating and found: 1) students have difficulty in understanding density, which was regarded as a subconcept of buoyancy. For example, approximately $19 \%$ students regarded the density of an object hanging in a liquid to be equal to that of a floating object, and $17 \%$ students believed "Density is the weight of an object in a liquid"; 2) students met difficulty in comparing the density between the emerged object and the liquid. About $6 \%$ students even believed "The density of an object hanging in a liquid is less than the density of the liquid"; 3) about 25\% students had difficulty in identifying the magnitude of buoyancy by differentiating an object's states. One misconception is that students think the magnitude of buoyancy is greater when the floating part of an object is greater. In addition, when comparing buoyancies of three objects which are in different states, such as sinking, hanging, and floating, they think the buoyancy of the sinking object is more than the others. If students can develop the relationship between an object's state and forces acting upon it, they can make the correct calculation and comparison between buoyancy and gravity. The study of Şahin and Çepni (2012) added two more misconceptions. The first one was about the identification of buoyancy, which was stated as "buoyancy force affects objects floating in the fluid, fluid buoyancy force does not affect objects submerged in the fluid and buoyancy force affects moving objects". The second one was about the 
direction of the buoyancy. Their study suggested that students might confuse the direction of buoyancy with the direction of gravity, especially when an object was sinking. In addition, even though some students know the direction of buoyancy is upward, they can't figure out whether it is perpendicular to the ground or to the container (Shao and Liu 2017).

Accordingly, we abstracted seven attributes of buoyancy. From the hierarchical property perspective, we abstracted Density, Submerged volume and Relative density. We did not add multilevel sub-concepts such as volume or mass as Yin and her colleagues (2005; 2008; 2008, 2014); rather, we incorporated volume and mass into Density and Submerged volume. We also adapted She's (2002, 2005) second attributes as Archimedes' theory, since the curriculums in China require students to calculate the buoyancy mathematically. From the misconception perspective, we abstracted Direction, Identification, and Relation with motion. We also realized that the hierarchical property perspective was related to the misconception perspective. That means that the sub-concepts also caused misconceptions. For example, there are many misconceptions around the sub-concepts density, submerged volume, etc. Therefore, we argued that these two perspectives are intertwined when we abstracted the seven attributes. The operational definitions of the attributes are given in Table 1 .

Table 1 Seven attributes of buoyancy and their operational definitions

\begin{tabular}{lll}
\hline \multicolumn{2}{c}{ Attribute } & Operational definition \\
\hline A1 & Direction & $\begin{array}{l}\text { Know that buoyancy is vertically upward. } \\
\text { Can identify not only gravity but also buoyancy that is exerted on } \\
\text { an object when it is floating, hanging, or sinking in liquid. } \\
\text { Know that density is a property of an object, which is equal to } \\
\text { mass divided by volume and will not change even though the mass } \\
\text { or the volume changes. } \\
\text { Anderstand the relationship between submerged volume in water } \\
\text { and actual volume. }\end{array}$ \\
A4 & Submerged volume & $\begin{array}{l}\text { Can develop the relationship between the magnitude of buoyancy } \\
\text { and the state of motion. } \\
\text { Can employ Archimedes' theory to calculate buoyancy. }\end{array}$ \\
A6 & Archimedes' theory & $\begin{array}{l}\text { Can judge floating and sinking by comparing the densities of the } \\
\text { object and of the liquid. }\end{array}$ \\
A7 & Relative Density &
\end{tabular}

\subsubsection{Sequence the attributes of the buoyancy into the hypothesized levels}


To sequence the attributes of buoyancy into the levels of the hypothesized learning progression, we first referred to another study conducted by our group member that aimed to detect the relationship of the same seven attributes (Chen 2015), and then organized a panel including physics educators and physics teachers to discuss and formulate the initial learning progression. Chen (2015) first formulated the initial relationship of the seven attributes theoretically and then employed a think-aloud approach to verify and refine the assumption. She collected data from six eighth grade students by employing eight open-ended items. The results indicated that attributes A1 and A2 formed the basis of A5, whereas A3 was the basis of both A6 and A7, and A4 was the basis of A6 (Figure 1).

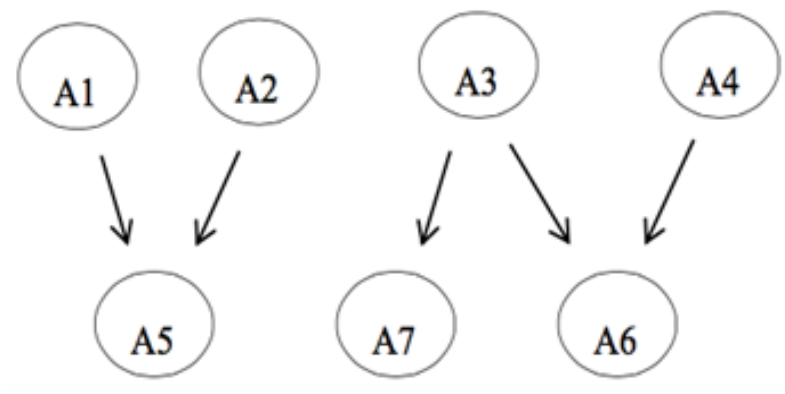

Figure 1 The relationship of the seven attributes

The panel first reviewed the relationships between the seven attributes and then discussed the patterns of students' understanding and the attributes in each level. Besides following the cumulative assumption, the panel also developed the levels according to the explanation model: IntuitiveQualitative-Quantitative-Integrative. Their main viewpoints included the following issues.

First, even before instruction, students could identify some attributes according to common experience. For example, the word buoyancy in Chinese indicates upward tendency or up thrust, therefore, Chinese students usually did not meet trouble to identify the direction of buoyancy (A1). Therefore, A1 was assigned to the intuitive level 0. Second, previous studies (Yin 2005; Yin et al. 2014) indicated that students preferred to use mass or volume to analyse sinking or floating even before instruction. However, considering that the students in our study had learned density prior to buoyancy, 
the students should prefer to use density or relative density to qualitatively explain sinking and floating. Therefore, they assigned the attributes A3 and A7 into the qualitative level 1. Third, in level 2, the quantitative level, the students should be able to employ Archimedes' theory to calculate the magnitude of buoyancy. Clement (2008) argued that the quantitative mental modelling was usually more complex than qualitative mental modelling. Finally, the panel asserted that the integrative level should indicate the relationship between buoyancy and motion. Force and motion is a big idea that requires students to understand not only buoyancy but also other forces such as gravity and also Newton's law. Considering this complexity, the panel split students' understanding of force and motion into two levels. The attribute A2 is added to level 3. This attribute indicates that students should be able to identify the buoyancy by observing the motion of an object. Although this level requires a higher ability, it is qualitative. Whereas in the higher quantitative level-level 4, students should be able to quantitatively establish the relationship between buoyancy and motion. This level is higher than the prior level. Thus, we obtained the hypothesized learning progression and its corresponding attributes (Table 2).

Table 2 Hypothesized learning progression and its corresponding attributes

\begin{tabular}{cccccccc}
\hline Level & A1 & A2 & A3 & A4 & A5 & A6 & A7 \\
\hline 0 & $\mathrm{x}$ & & & & & & \\
1 & $\mathrm{x}$ & & $\mathrm{x}$ & & & $\mathrm{x}$ \\
2 & $\mathrm{x}$ & & $\mathrm{x}$ & $\mathrm{x}$ & $\mathrm{x}$ & $\mathrm{x}$ \\
3 & $\mathrm{x}$ & $\mathrm{x}$ & $\mathrm{x}$ & $\mathrm{x}$ & & $\mathrm{x}$ & $\mathrm{x}$ \\
4 & $\mathrm{x}$ & $\mathrm{x}$ & $\mathrm{x}$ & $\mathrm{x}$ & $\mathrm{x}$ & $\mathrm{x}$ & $\mathrm{x}$ \\
\hline
\end{tabular}

\subsection{Validating Learning Progression}

The central concept of latent class analysis is that the population of interest is composed of unobserved classes. This approach is well-suited for analysing learning progression data because it aligns closely with the notion that students can be classified into one of several progression levels that explain their responses. It has also been broadly applied and discussed in learning progression research 
(Fulmer et al. 2014; Steedle and Shavelson 2009). There are two kinds of latent class analysis that depend on different assumptions: confirmatory analysis and exploratory analysis. In this study, we use an exploratory analysis, which can determine the number of latent classes that would provide us evidence for suitable progression levels.

Through latent class analysis, we can only partly verify the initial learning progression. We still can't ensure the specific attribute mastery pattern (AMP) established in our learning progression hypothesis. To move forward, we proceed with a Rule Space Model analysis that has been used in learning progression (Chen et al. 2017; Chen et al. 2016). The rule space model (Tatsuoka 1983) is one of the cognitive diagnostic models that can provide students' profiles on skills or attributes through the observed item responses. It begins with a Q matrix that indicates the relationship between items and attributes. Students are then classified into different attribute mastery patterns (AMPs). For more details on the application of RSM to learning progression, see Chen et al. (2016). According to the result of latent class analysis with rule space model analysis, we can answer the two research questions in this study.

\section{Method}

\subsection{Item Design}

According to the AMP of each learning progression level, physics researchers, physics teachers, and measurement experts collaborated to recruit, revise, and produce items for each level. Most items involved more than one such attribute, whereas a few items possessed only one attribute. For instance, item 3 involved attributes 3 and 4, whilst item 1 only involved attribute 1 . After a pilot test, 14 multichoice items were included in the final Buoyancy test (see Appendix), with one item at level 0, three items at level 1, four at level 2, two at level 3, and four at level 4 (Table 3). In addition, these items 
examine students' different attributes. For instance, item 1 only involves A1, whilst item 14 examines all seven attributes. We assumed that the items at each level were able to differentiate students that were located in a certain level from those located in the neighbouring levels. For instance, an individual $L$ who was categorized in level 1 should have a lower probability of mastering the level 2 items than an individual $H$ who was categorized at a higher level. However, no significant difference should be observed in terms of the probability to correctly answer the level 1 items for $L$ and $H$. In this test, each item was dichotomously scored as " 1 " for correct and as " 0 " for incorrect.

Table 3 Hypothesized Learning Progression Level and its corresponding items

\begin{tabular}{|c|c|c|c|c|c|c|c|c|}
\hline Level & Item & A1 & $\mathrm{A} 2$ & A3 & A4 & A5 & A6 & A7 \\
\hline 0 & 1 & 1 & 0 & 0 & 0 & 0 & 0 & 0 \\
\hline \multirow{3}{*}{1} & 3 & 0 & 0 & 1 & 0 & 0 & 0 & 0 \\
\hline & 5 & 0 & 0 & 1 & 0 & 0 & 0 & 1 \\
\hline & 6 & 0 & 0 & 1 & 0 & 0 & 0 & 1 \\
\hline \multirow{4}{*}{2} & 4 & 0 & 0 & 0 & 1 & 0 & 0 & 0 \\
\hline & 12 & 1 & 0 & 1 & 1 & 0 & 1 & 1 \\
\hline & 10 & 0 & 0 & 1 & 1 & 0 & 1 & 0 \\
\hline & 9 & 0 & 0 & 1 & 1 & 0 & 0 & 0 \\
\hline \multirow{2}{*}{3} & 2 & 0 & 1 & 0 & 0 & 0 & 0 & 0 \\
\hline & 13 & 1 & 1 & 1 & 1 & 0 & 1 & 1 \\
\hline \multirow{4}{*}{4} & 7 & 1 & 1 & 0 & 0 & 1 & 0 & 0 \\
\hline & 8 & 1 & 1 & 0 & 0 & 1 & 0 & 0 \\
\hline & 11 & 1 & 1 & 1 & 0 & 1 & 0 & 1 \\
\hline & 14 & 1 & 1 & 1 & 1 & 1 & 1 & 1 \\
\hline
\end{tabular}

\subsection{Participants and Data Collection}

We recruited 1089 grade eight students to attend this test in ten middle schools located in five east coast cities in China. All students used identical textbooks and all had formally learnt the buoyancy concept in their science class by the time the test was taken. All students took a 40-minute test. They were promised that their personal information would remain private. Tests in different schools were not conducted at the same time because of a restricted number of test administrators. However, the schools 
did not communicate about the test, ensuring the validity of the results. After deleting invalid subjects with blank questionnaires, 1036 were left. Among these participants, there are $51.1 \%$ boys, $48.6 \%$ girls, and $0.3 \%$ unknown.

\subsection{Data Analysis}

We first examined the psychometric quality of the test under the Classical Test Theory (CTT) framework by employing SPSS 20.0. Latent class analysis was conducted to partly verify the initial hypothesized learning progression corresponding to our first research question. In this analysis, a series of models with 3, 4, 5, and 6 classes were estimated using Mplus 7 (Muthén and Muthén 2012). The model with the best model fit according to the Bayesian Information Criterion (BIC) was chosen for the learning progression verification (Schwarz 1978). Lastly, we used the Rule Space Model analysis to identify the specific AMP for each level to address the second research question using MATLAB code

(Li et al. 2009).

\section{Results}

\subsection{Reliability Analysis}

The CTT framework takes the percentage of correct response as the item difficulty parameter and the item-total correlation as the item discrimination parameter. A good item is identified by an item difficulty value that is not too high $(<0.70)$ or not too low $(>0.30)$, or a high item discrimination value. The common cut-off criterion for item discrimination is 0.20 (Adams, 2002). The obtained parameters are found in Table 4 . The difficulty indices of all items are above 0.30 , with an average of 0.67 $(\mathrm{SD}=0.17)$. But five of these items difficulty values are higher than 0.70 , indicating they are too easy for students. In the framework of CTT, difficulty value can be greatly affected by the sample. It is worth noting that students had been taught these contents when they took test in this study. This may 
explain why some items are so easy for students. However, even though these items are easy, we still need to include them in the test to guarantee the completeness of test content. The discrimination indices of all items are above 0.20 , with an average of $0.60(\mathrm{SD}=0.15)$, satisfying the cut-off criterion. Table 4 Item difficulty and item discrimination from the CTT analysis

\begin{tabular}{cccccc}
\hline Item & Difficulty & Discrimination & Item & Difficulty & Discrimination \\
\hline 1 & 0.944 & 0.342 & 8 & 0.616 & 0.456 \\
2 & 0.597 & 0.687 & 9 & 0.671 & 0.582 \\
3 & 0.891 & 0.466 & 10 & 0.620 & 0.697 \\
4 & 0.710 & 0.534 & 11 & 0.556 & 0.681 \\
5 & 0.847 & 0.587 & 12 & 0.663 & 0.813 \\
6 & 0.903 & 0.412 & 13 & 0.542 & 0.835 \\
7 & 0.561 & 0.645 & 14 & 0.318 & 0.718 \\
\hline
\end{tabular}

\subsection{Latent class analysis}

To verify the hypothesized learning progression, we conducted a latent class analysis with 3, 4, 5, and 6 clusters. Based on statistical fit in terms of BIC and a bootstrapped likelihood ratio test, the 5cluster model demonstrated the best fit to the data (Table 5).

Table 5 Latent Class Analysis Fit Statistics $(N=1036)$

\begin{tabular}{ccc}
\hline Model & $\chi^{2}$ & BIC \\
\hline 3-cluster & 3743.037 & 12378.840 \\
4-cluster & 3295.755 & 12315.715 \\
5-cluster & $\mathbf{3 0 8 7 . 9 9 2}$ & $\mathbf{1 2 2 9 5 . 3 4 3}$ \\
6-cluster & 3090.687 & 12336.599 \\
\hline
\end{tabular}

Therefore, we employed the 5-cluster model to verify our assumption. Specifically, an item was indeed being "at the level" if it supported an interpretation that students who reach that level would be able to solve or complete the task, whereas students at the lower levels would be unlikely to be successful. To verify these items, the conditional probability table was examined (Table 6) which showed the probability of correctly answering items of each level. For example, item 3 was supposed to examine A3 of level 1, so this item should discriminate students who were at level 0 and level 1. As 
shown in Table 6 , cluster 1 students have a lower probability $(0.364)$ than students in cluster $2(0.959)$.

After examining all 14 items, we concluded that all these items had good performance discriminating

students between clusters. Also, we concluded that students at cluster 1 are at level 0 , students of

cluster 2 are at level 1, and so on. Analysis of variances (ANOVA) was used to investigate differences

in personal total score with respect to students in different progression levels. The result showed

students in these different levels are indeed statistically significant, $F(4,1031)=2592.943, p<0.000$,

$\eta^{2}=0.91$

Table 6 Latent Class Analysis Results

\begin{tabular}{|c|c|c|c|c|c|c|c|}
\hline \multirow{2}{*}{ Level } & \multirow{2}{*}{ Item } & \multirow{2}{*}{ Response } & \multicolumn{5}{|c|}{ Latent Variable } \\
\hline & & & Cluster $=1$ & Cluster $=2$ & Cluster $=3$ & Cluster $=4$ & Cluster $=5$ \\
\hline 0 & 1 & 1 & 0.773 & 0.931 & 0.926 & 0.988 & 0.994 \\
\hline \multirow[t]{3}{*}{1} & 3 & 1 & 0.364 & 0.959 & 0.991 & 0.954 & 0.986 \\
\hline & 5 & 1 & 0.171 & 0.87 & 0.957 & 0.954 & 0.996 \\
\hline & 6 & 1 & 0.534 & 0.903 & 0.981 & 0.988 & 0.973 \\
\hline \multirow[t]{4}{*}{2} & 9 & 1 & 0.218 & 0.453 & 0.745 & 0.754 & 0.916 \\
\hline & 4 & 1 & 0.355 & 0.443 & 0.897 & 0.777 & 0.934 \\
\hline & 10 & 1 & 0.082 & 0.185 & 0.904 & 0.803 & 0.923 \\
\hline & 12 & 1 & 0.067 & 0.118 & 0.968 & 0.967 & 0.998 \\
\hline \multirow[t]{2}{*}{3} & 2 & 1 & 0.176 & 0.307 & 0 & 0.813 & 0.948 \\
\hline & 13 & 1 & 0 & 0.006 & 0.082 & 0.879 & 0.987 \\
\hline \multirow[t]{4}{*}{4} & 7 & 1 & 0.204 & 0.306 & 0.251 & 0.559 & 0.941 \\
\hline & 8 & 1 & 0.395 & 0.508 & 0.352 & 0.51 & 0.905 \\
\hline & 11 & 1 & 0.067 & 0.319 & 0.346 & 0.537 & 0.964 \\
\hline & 14 & 1 & 0 & 0 & 0.011 & 0.037 & 0.907 \\
\hline \multicolumn{3}{|c|}{ Numbers of Students } & 136 & 228 & 85 & 235 & 352 \\
\hline \multicolumn{3}{|c|}{ Latent Class Probability (\%) } & 13.13 & 22.01 & 8.21 & 22.68 & 33.98 \\
\hline
\end{tabular}

\subsection{Rule Space Model Analysis}

To illustrate how students of different levels progress when learning the concept of buoyancy, we

classified these students into different AMPs according to the Mahalanobis distance. Result showed 
that 1036 students were classified into 37 AMPs. None of the students were classified into AMP 1 (0000000), AMP 5 (0001000) and AMP 24 (0111000). Almost 50\% of students were classified into three AMPs: AMP 35 (1111101), AMP 39 (1111011), and AMP 40 (1111111). Specifically, there were 6.7\% students in AMP 35 who had mastered all six attributes but A6, 11.3\% students who were distributed to AMP 39 have attained six attributes except A5, and 30.9\% students who had already mastered all the seven attributes. This result indicates that almost half of students in this test have a good understanding of these attributes after their respective learning sessions at school.

Then, we summed up and compared different kinds of AMPs in each level (Table 7). Students of level 4 are classified into three AMPs. Most students are in AMP 40 (1111111). Students of level 3 are classified into ten AMPs but there are some AMPs that include only a very small amount of students such as AMP 27 (1101100) with only 1 student. We deleted such AMPs that had students less than the average amount (The average of level $3=235 / 10$ ). The same procedure was applied to levels 2,1 and 0 . After deletion, there are three AMPs left in level 3. As Table 7 shows, most students in level 3 are in AMP 39 (1111011). Students of level 2 are also mainly classified into three AMPs and most students are in AMP 37 (1011011). Students of level 1 are mainly classified into nine AMPs. Most students are in AMP 38 (0111011) and AMP 30 (1011001). Students of level 0 are mainly classified into ten AMPs and most students are in AMP 8 (0010001).

Table 7 Numbers of students and AMPs in each level

\begin{tabular}{|c|c|c|c|c|c|c|c|c|c|c|c|c|}
\hline AMP_ID & A1 & A2 & A3 & A4 & A5 & A6 & A7 & Level0 & Level1 & Level2 & Level3 & Level4 \\
\hline 40 & $\mathrm{x}$ & $\mathrm{x}$ & $\mathrm{x}$ & $\mathrm{x}$ & $\mathrm{x}$ & $\mathrm{x}$ & $\mathrm{x}$ & & & & & 320 \\
\hline 39 & $\mathrm{X}$ & $\mathrm{x}$ & $\mathrm{x}$ & $\mathrm{X}$ & & $\mathrm{X}$ & $\mathrm{x}$ & & & 17 & 99 & \\
\hline 38 & & $\mathrm{x}$ & $\mathrm{X}$ & $\mathrm{X}$ & & $\mathrm{X}$ & $\mathrm{X}$ & & 27 & 16 & 26 & \\
\hline 37 & $\mathrm{x}$ & & $\mathrm{x}$ & $\mathrm{X}$ & & $\mathrm{X}$ & $\mathrm{X}$ & & & 27 & & \\
\hline 36 & & & $\mathrm{x}$ & $\mathrm{X}$ & & $\mathrm{X}$ & $\mathrm{X}$ & & 14 & & & \\
\hline 35 & $\mathrm{x}$ & $\mathrm{x}$ & $\mathrm{x}$ & $\mathrm{X}$ & $\mathrm{x}$ & & $\mathrm{x}$ & & & & 89 & 23 \\
\hline 34 & $\mathrm{x}$ & $\mathrm{x}$ & $\mathrm{x}$ & & $\mathrm{x}$ & & $\mathrm{x}$ & & 16 & & & \\
\hline
\end{tabular}




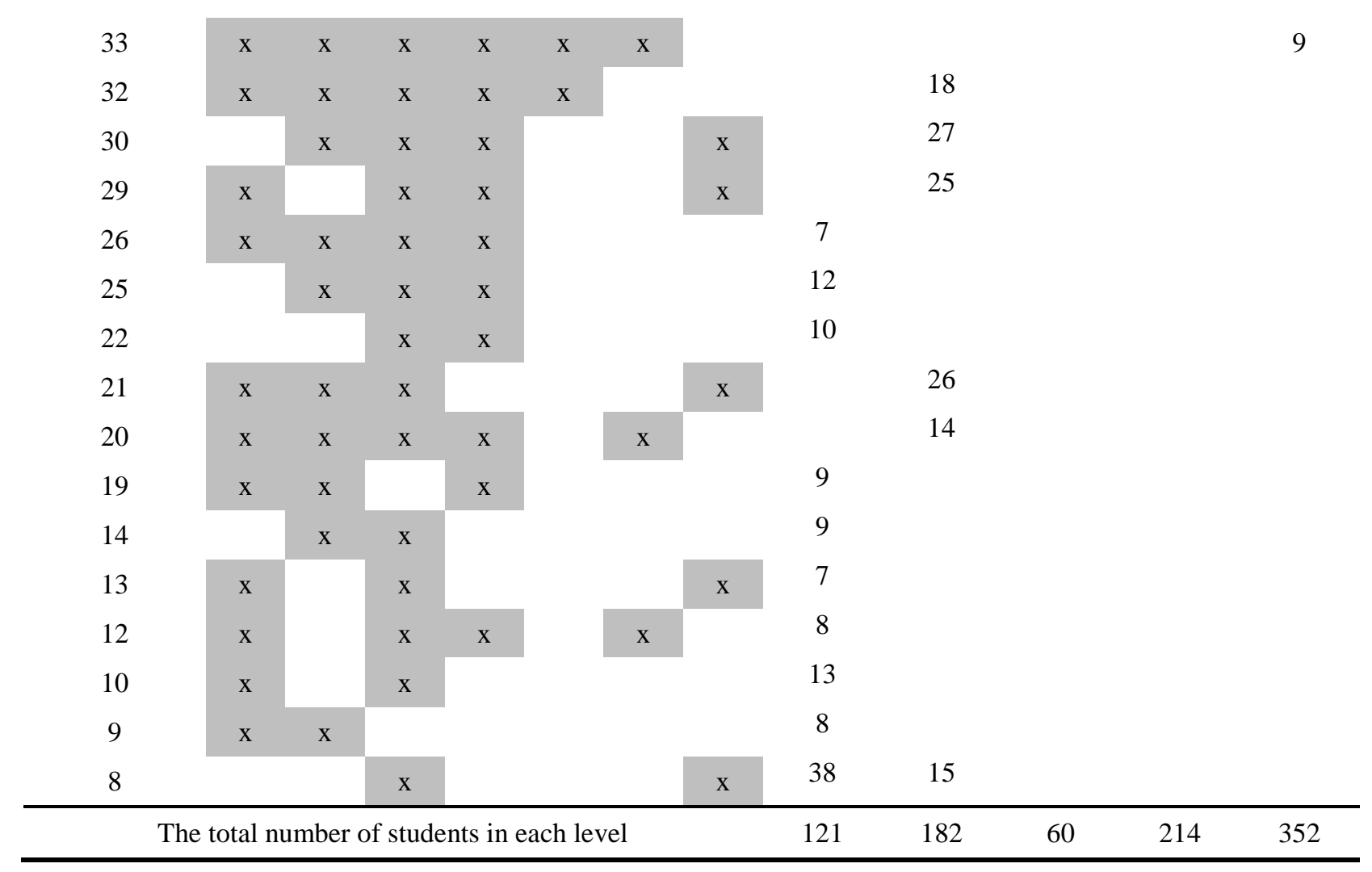

We also examined students' attribute master probability of each level (Table 8). When judging

whether students have mastered some attributes, we set $0.5\left(p^{*}\right)$ as the criterion, which means students

have a $50 \%$ opportunity to correctly acquire a given attribute. Results show that students at level 0 only

understand A3. When students progress to level 1, they can grasp A1, A2, A3, A4 and A7. Students in

levels 2 and 3 have mastered the same attributes: A1, A2, A3, A4, A5 and A7. Students in level 4 can

master all seven attributes.

Table 8 Attribute master probability $\left(p^{*}\right)$ of each level

\begin{tabular}{cccccccc}
\hline Level & A1 & A2 & A3 & A4 & A5 & A6 & A7 \\
\hline 0 & 0.43 & 0.37 & 0.86 & 0.38 & 0 & 0.07 & 0.37 \\
1 & 0.54 & 0.70 & 1.0 & 0.69 & 0.19 & 0.30 & 0.82 \\
2 & 0.73 & 0.55 & 1.0 & 1.0 & 0 & 1.0 & 1.0 \\
3 & 0.88 & 1.0 & 1.0 & 1.0 & 0.42 & 0.58 & 1.0 \\
4 & 1.0 & 1.0 & 1.0 & 1.0 & 1.0 & 0.93 & 0.97 \\
\hline
\end{tabular}

Therefore, a modified learning progression showing the progress of learning buoyancy was obtained

(Table 9). It is somewhat different from the hypothesized learning progression, especially for levels 0 , 
1, and 2. Specifically, we assumed that students at level 0 can only master Direction based on their common experience. However, students at this level can only grasp Density, which has been taught before the learning session of buoyancy. Compared to students at level 0, level 1 students achieved significant progress. They mastered Direction, Identification, Submerged volume and Relative Density along with Density. This is not consistent with our hypothesis that assumed students at this level can only master Direction, Density and Relative Density. Archimedes' theory can be regarded as an important sign when judging whether students progress to level 2. Since students have mastered Identification at level 1, students in levels 2 and 3 can't be distinguished as we assumed only students in level 3 or above can master Identification. Thus, we combine the original levels 2 and 3 into one level-level 2. Accordingly, level 4 was modified as level 3, which is the level where students have mastered all seven attributes.

Table 9 Modified Learning Progression and its corresponding attributes

\begin{tabular}{cccccccc}
\hline Level & A1 & A2 & A3 & A4 & A5 & A6 & A7 \\
\hline 0 & & & $\mathrm{x}$ & & & & \\
1 & $\mathrm{x}$ & $\mathrm{x}$ & $\mathrm{x}$ & $\mathrm{x}$ & & $\mathrm{x}$ & $\mathrm{x}$ \\
2 & $\mathrm{x}$ & $\mathrm{x}$ & $\mathrm{x}$ & $\mathrm{x}$ & & $\mathrm{x}$ & $\mathrm{x}$ \\
3 & $\mathrm{x}$ & $\mathrm{x}$ & $\mathrm{x}$ & $\mathrm{x}$ & $\mathrm{x}$ & $\mathrm{x}$ & \\
\hline
\end{tabular}

\section{Discussion}

\subsection{Modeling Conceptual Change by a Learning Progression}

By employing quantitative methods, this study empirically validated the cumulative characteristics of conceptual change. This result was consistent with prior studies (diSessa 2007, 2013). However, several new results were also found. First, we modelled the conceptual change process by a learning progression. This learning progression approach, by decomposing the attributes of the concept of buoyancy, was able to locate not only the starting point and the ending point of the conceptual change, 
but also the incremental steps students pass through. In the current study, students' progressions were modelled by examining how many attributes they mastered. For example, students at level 0 only mastered one attribute, whereas five attributes were mastered in level 1, six in level 2 and seven in level 3. This result indicates that students' conceptual change happens as they understand more attributes of buoyancy, which essentially accords with studies exploring the topic "Why Things Sink or Float" (Kennedy and Wilson 2007; Yin et al. 2014). Second, this study provided quantitative evidence to support the cumulative characteristic of conceptual change. Compared with prior studies which mainly employed theoretical or qualitative methods (Magnusson et al. 1997; Vosniadou and Brewer 1992), this study quantitatively depicted how students' conceptual change happened. Furthermore, a large sample size ensured the reliability of the results.

\subsection{Verifying the Learning Progression of Buoyancy}

By employing latent class analysis and rule space model analysis, we refined our initial learning progression of buoyancy. First, as mentioned above, the expert panel hypothesized that the students in level 0 only mastered Direction, but in our study, we found that the lowest level students only understood Density. This disaccord should be carefully interpreted. One possibility is that Density is indeed much easier than Direction as our finding shows due to the learning sequence (Chen et al. 2016). Density is defined as a property of an object determined by its mass and volume. Students in this study were taught density at the first semester of the $7^{\text {th }}$ grade. In contrast, they were taught the other six attributes at the first semester of the $8^{\text {th }}$ grade. Thus Density is easiest among these seven attributes and students in level 0 grasped only this attribute. Another possibility for the unexpected result could be the nature of the items. In this test, 5 of 14 items have difficulties that are greater than 0.7 . We examined 
them and found that 3 items included density. Therefore, it is likely that these items are too easy to effectively evaluate the attribute of density.

When students progress to level 1, they can grasp two more attributes-Identification and Submerged volume - compared to what the panel assumed. Identification means that students can identify not only gravity but also buoyancy. It directly contributed to the mastery of Relation with motion, which indicates that students can analyze the magnitude of buoyancy according to the state of motion. Considering that students have learnt balanced forces at the second semester of the $7^{\text {th }}$ grade, it can be easily transferred to Identification, which analyzes buoyancy and gravity, even though students have pre-instructional conceptions before formal instruction (Şahin and Çepni 2012; Ünal and Costu 2005). So Identification is located in level 1. As for Submerged volume, it is the foundation of Archimedes' theory. Considering the hierarchical property of these two attributes, the previous operation of putting them into one level-level 2-is not reasonable. This is because higher hierarchical level concepts are more difficult to learn (She 2002). As our result shows, students gradually mastered these concepts_-Submerged volume in level 1 and Archimedes' theory in level 2. What's more, the Submerged volume can be understood by a qualitative model, whereas Archimedes' theory must be grasped by a quantitative model. Clement (2008) claimed that the quantitative mental model was more complex than the qualitative mental model. Therefore, we put Submerged volume in level 1 instead of level 2.

Finally, the results showed that students had the same attribute mastery pattern in original levels 2 and 3. The panel divided level 2 and level 3 by Identification in the hypothesized learning progression. In the modified learning progression, Identification can be mastered by students at level 1 and above, so students in original levels 2 and 3 can't be distinguished any more. Thus, we combined original 
levels 2 and 3 into one level-level 2 and reduced the 5-level hypothesized learning progression into a modified 4-level learning progression.

Accordingly, we arrived at a revised explanation model: Qualitative-Quantitative-Integrative. Compared with the initial explanation model, we exclude the Intuitive part of the model, which described some attributes that are easy to learn by common experience. There are two possible reasons why students don't give priority to Direction. The first one is that students might know the direction of buoyancy is upward from their everyday experience. However, they might confuse the accurate direction, such as whether it is perpendicular to the ground or perpendicular to the container. The second possibility is that items involving direction are too difficult. We examined the Buoyancy test and found that seven items involved the direction concept, while four of them also examined other difficult attributes, such as A5, which results in the inaccurate inference about the difficulty of the direction concept. The attributes in the new level 0 appear to result from a prior-learning effect and they can be explained by a Qualitative model together with attributes in level 1 . When students get into level 2, they can calculate buoyancy by Archimedes' theory and the Quantitative explanation model is applicable. At last, students in level 3 can master the attribute of Relation with motion and the Integrative explanation model is also suitable.

In this study, we firstly provided a new perspective for determining the grain size in a learning progression. Grain size can be defined as the content of each level or as the size of the shift between levels (Alonzo and Gotwals 2012). No single grain size is suitable for all learning progressions and it is mainly determined by the aim of the learning progression. Teachers and curriculum developers tend to need a fine-grained learning progression to identify students' weaknesses. The content of attributes we used as grain size in our work is quite applicable to such a case. Second, Archimedes' theory and 
Relation with motion are the key attributes for students to fully understand buoyancy. Teachers should give more instructions to facilitate the understanding of these attributes and achieve the desired conceptual change (Hardy et al. 2006). Actually, there are already some existing studies focusing on the phenomenon of objects' floating and sinking (Kennedy and Wilson 2007; Yin et al. 2014). But their results may be not applicable for Chinese students because Kennedy and Wilson (2007) and Yin et al. (2014) paid much attention to density and relative density. In Chinese textbooks, students learn buoyancy from the perspective of force. Direction, magnitude, and application point are basic elements of force. When it comes to the topic of buoyancy, science or physics teachers give instructions in identifying the direction and calculating the magnitude of buoyancy. Compared with the contents in some researches (Kennedy and Wilson 2007; Yin et al. 2014), relative density is only a sub-concept which can be derived from the Archimedes' theory in China. Thus, we need to include other attributes such as Archimedes' theory and Relation with motion besides Density and Relative density. This finding provides more evidence for scholars and teachers to understand how students' conceptual change of buoyancy happens, and leads to specific instructional hints for physics or science teachers. Thirdly, compared with previous studies which only applied latent class analysis (Fulmer et al. 2014; Steedle and Shavelson 2009) or only used the rule space model (Chen et al. 2017; Chen et al. 2016), we used both approaches. We can summarize the benefits of such an analysis in the following way. We first used latent class analysis to group the cohort of students into more objective levels compared with Chen et al. (2016) and Chen et al. (2017). Furthermore, we used the rule space model analysis to provide more detailed evidence of the attributes in each level compared with Fulmer et al. (2014).

However, it is necessary to point out limitations in this work and steps we are currently devoted to. The first limitation is the difficulty of the attributes we judged. The attribute difficulty can be 
influenced by the characteristics of the items used. If tested only by difficult items, the judgment of the difficulty of an attribute will be overestimated, just as A1 in our work. One solution is to balance the number of difficult items and easy items. Second, the validity of the revised learning progression has not yet been supported by implementation in the classroom. Learning progression is a powerful framework for improving science teaching and student learning. Future studies should design experiments to compare traditional teaching group students with learning-progression-based group students.

\section{Conclusion}

We have made progress toward modelling the cumulative characteristic of conceptual change by developing a learning progression of buoyancy. Overall, the conceptual change of buoyancy is modelled by a 4-level learning progression and students' progression to higher levels is accompanied by an increased number of mastered attributes. Students at level 0 only understand Density. When students progress to level 1, they can grasp Direction, Identification, Submerged volume and Relative density on the basis of the prior level. Then, students gradually master Archimedes' theory and reach level 2. The most advanced students can grasp Relation with motion and get into level 3. The

Qualitative-Quantitative-Integrative model accounts for the 4-level learning progression well.

\section{References}

Alonzo, A. C., \& Gearhart, M. (2006). Considering learning progressions from a classroom assessment perspective. Measurement: Interdisciplinary Research and Perspectives, 14, 99-104.

Alonzo, A. C., \& Gotwals, A. W. (2012).Learning progressions in science: current challenges and future directions.In A. Alonzo \& A. Gotwals (Eds.) Learning progressions in science (pp. 257292). The Netherlands: SensePublishers.

Alonzo, A. C., \& Steedle, J. T. (2009). Developing and assessing a force and motion learning progression. Science Education, 93(3), 389-421.

Chen, F., Yan, Y., \& Xin, T. (2017). Developing a learning progression for number sense based on the rule space model in China. Educational Psychology, 37, 1-17.

Chen, F., Zhang, S. S., Guo, Y. F., \& Xin, T. (2016). Applying the Rule Space Model to develop a learning progression for thermochemistry. Research in Science Education, doi: 10.1007/s11165- 
016-9553-7.

Chen, Y. (2015). Cognitive diagnosis and remedial teaching on junior middle school students' concepts of buoyancy. Unpublished master dissertation. Zhe Jing: Zhe Jing Normal University.

Chi, M. T. H., Slotta, J. D., \& De Leeuw, N. (1994). From things to processes: a theory of conceptual change for learning science concepts. Learning and Instruction, 4(1), 27-43.

Chi, M. T. H. (1992). Conceptual change across ontological categories: examples from learning and discovery in science. In R. Giere (Eds.) Cognitive models of science: Minnesota studies in the philosophy of science (pp. 129-186). Minneapolis: University of Minnesota Press.

Chi, M. T. H., Roscoe, R. D., Disessa, A. A., Vosniadou, S., Ivarsson, J., Schoultz, J., . . Pintrich, P. R. (2003). Reconsidering conceptual change: Issues in theory and practice. Science Education, 87(6), 913-916.

Clement, J. (2008). The role of explanatory models in teaching for conceptual change. In S. Vosniadou (Eds.)International handbook of research on conceptual change (pp. 417-452). New York: Routledge.

diSessa, A. A. (1988). Knowledge in pieces. In G. Forman \& P. B. Pufall (Eds.), Constructivism in the computer age (pp. 49-70). Hillsdale: Erlbaum.

diSessa, A. A. (2007). Changing conceptual change. Human Development, 50(1), 39-46.

diSessa, A. A. (2013). A bird's-eye view of the "pieces" vs. "coherence" controversy (from the "pieces" side of the fence"). In S. Vosniadou (Eds.), International handbook of research on conceptual change (pp. 31-48). New York: Routledge.

diSessa, A. A., Gillespie, N. M., \& Esterly, J. B. (2004). Coherence versus fragmentation in the development of the concept of force. Cognitive Science, 28(6), 843-900.

diSessa, A. A. (1993). Toward an epistemology of physics. Cognition and Instruction, 10, 105-225.

Duschl, R. A., Schweingruber, H. A., \&Shouse, A. W. (2007). Taking science to school:Learning and teaching science in grades $K-8$. Washington: National Academics.

Fulmer, G. W., Liang, L. L., \& Liu, X. (2014). Applying a force and motion learning progression over an extended time span using the force concept inventory. International Journal of Science Education, 36(17), 2918-2936.

Guzzetti, B. J. (1993). Critical review of qualitative research on conceptual change from science education. Paper presented at the annual meeting of the National Reading Conference, Charleston, SC.

Hardy, I., Jonen, A., Möller, K., \& Stern, E. (2006). Effects of instructional support within constructivist learning environments for elementary school students' understanding of "floating and sinking". Journal of Educational Psychology, 98(2), 307-326.

Havu-Nuutinen, S. (2005). Examining young children's conceptual change process in floating and sinking from a social constructivist perspective. International Journal of Science Education, 27(3), 259-279.

Joung, Y. J. (2009). Children's typically-perceived-situations of floating and sinking. International Journal of Science Education, 31(1), 101-127.

Kennedy, C. A., \& Wilson, M. (2007). Using progress variables to interpret student achievement and progress. Berkeley: University of California, BEAR Center.

Loverude, M. E., Kautz, C. H., \& Heron, P. R. L. (2003). Helping students develop an understanding of Archimedes' principle. I. Research on student understanding. American Journal of Physics, 71(11), 1178-1187. 
Li, F., Yu, N., \& Xin, T. (2009). Development of diagnostic math test for grade 4 and grade 5 based on the rule space model. Psychological Development and Education, 3, 113-118.

Maclin, D., Grosslight, L., \& Davis, H. (1997). Teaching for understanding: a study of students' preinstruction theories of matter and a comparison of the effectiveness of two approaches to teaching about matter and density. Cognition and Instruction, 15(3), 317-393.

Magnusson, S. J., Templin, M., \& Boyle, R. A. (1997). Dynamic science assessment: a new approach for investigating conceptual change. Journal of the Learning Sciences, 6(1), 91-142.

McCloskey, M. (1983a). Intuitive physics. Scientific American, 248(4), 122-130.

McCloskey, M. (1983b). Naive theories of motion. In D. Gentner \& A. L. Stevens (Eds.), Mental models (pp. 299 - 324). Hillsdale, NJ: Erlbaum.

Mills, R., Tomas, L., \& Lewthwaite, B. (2016). Learning in earth and space science: a review of conceptual change instructional approaches. International Journal of Science Education, 38(5), 124.

Muthén, L. K., \& Muthén, B. O. (2012). Mplus user's guide (7th ed.). Los Angeles: Muthen \& Muthen.

Neumann, K., Viering, T., Boone, W. J., \& Fischer, H. E. (2013). Towards a learning progression of energy. Journal of Research in Science Teaching, 50(2), 162-188.

Norman, D. A., \& Rumelhart, D. E. (1981). The LNR approach to human information processing. Cognition, 10, 235.

National Research Council. (2001). Knowing what students know. Washington: National Academy Press.

National Research Council. (2007). Taking science to school; learning and teaching science in grades K-8 (R.A. Duschl, H.A. Schweingruber, \& A.W. Shouse, Eds.). Washington DC: The National Academic Press.

Piaget, J. (1930). The child's conception of causality. London: Kegan Paul.

Piaget, J. (1969). The child's conception of physical causality. Totowa: Littlefield.

Posner, G. J., Strike, K. A., Hewson, P. W., \& Gertzog, W. A. (1982). Accommodation of a scientific conception: Toward a theory of conceptual change. Science Education, 66(2), 211-227.

Şahin, Ç., \& Çepni, S. (2012). Effect of different teaching methods and techniques embedded in the 5E instructional model on students' learning about buoyancy force. Eurasian Journal of Physics and Chemistry Education, 4(2), 97-127.

Schwarz, G. (1978). Estimating the dimension of a model. Annals of Statistics, 6(2), 15-18.

Shao, J. X. \& Liu, M. (2017). The design and improvement of buoyancy experiment teaching. Teaching \& Administration, 31, 63-65.

She, H. C. (2002). Concepts of a higher hierarchical level require more dual situated learning events for conceptual change: a study of air pressure and buoyancy. International Journal of Science Education, 24(9), 981-996.

She, H. C. (2005). Enhancing eighth grade students' learning of buoyancy: the interaction of teachers' instructional approach and students' learning preference styles. International Journal of Science and Mathematics Education, 3(4), 609.

Smith, C. L., Carey, S., \& Wiser, M. (1985). On differentiation: a case study of the development of the concepts of size, weight, and density. Cognition, 21(3), 177.

Smith, C. L., Wiser, M., Anderson, C. W., \& Krajcik, J. (2006). Implications of research on children's learning for standards and assessment: aproposed learning progression for matter and theatomicmolecular theory. Measurement: Interdisciplinary Research and Perspectives, 4, 1-98. 
Songer, N. B., Kelcey, B., \& Gotwals, A. W. (2009). How and when does complex reasoning occur? Empirically driven development of a learning progression focused on complex reasoning about biodiversity. Journal of Research in Science Teaching, 46(6), 610-631.

Soto Lombana, C., Otero, J., \& Sanjosé López, V. (2005). A Review of Conceptual Change Research in Science Education. Revista De Educación En Ciencias.

Steedle, J. T., \& Shavelson, R. J. (2009). Supporting valid interpretations of learning progression level diagnoses. Journal of Research in Science Teaching, 46(6), 699-715.

Stevens, S. Y., Delgado, C., \& Krajcik, J. S. (2010). Developing a hypothetical multi-dimensional learning progression for the nature of matter. Journal of Research in Science Teaching, 47(6), $687-715$.

Taber, K. S. (2010). Understanding the Nature and Processes of Conceptual Change: An Essay Review. Education Review.

Talanquer, V. (2009). On cognitive constraints and learning progressions: the case of "structure of matter". International Journal of Science Education, 31(15), 2123-2136.

Tatsuoka, K. K. (1983). Rule space: an approach for dealing with misconceptions based on item response theory. Journal of Educational Measurement, 20(4), 345-354.

Ünal, S., \& Costu, B. (2005). Problematic issue for students: does it sink or float? Asia-Pacific Forum on Science Learning and Teaching, 6(1), 1.

Vosniadou, Stella, Brewer, \& William, F. (1987). Theories of knowledge restructuring in development. review of educational research, 57(1), 51-67.

Vosniadou, S. (1994). Capturing and modeling the process of conceptual change. Learning and Instruction, 4(1), 45-69.

Vosniadou, S., \& Brewer, W. F. (1992). Mental models of the earth: A study of conceptual change in childhood. Cognitive Psychology, 24(4), 535-585.

Wilson, M. (2005). Constructing measures: an item response modeling approach. Mahwah: Lawrence Erlbaum Associates.

Wilson, M. (2009). Measuring progressions: assessment structures underlying a learning progression. Journal of Research in Science Teaching, 46(6), 716-730.

Wilson, M. R., \& Bertenthal, M. W. (2005). Systemes for state science assessment. Washington DC: The National Academic Press.

Yin, Y. (2005). The influence of formative assessments on student motivation, achievement, and conceptual change. Unpublished doctoral dissertation. Stanford: Stanford University.

Yin, Y., Shavelson, R. J., Ayala, C. C., Ruiz-Primo, M. A., Brandon, P. R., Furtak, E. M., . . Young, D. B. (2008). On the impact of formative assessment on student motivation, achievement, and conceptual change. Applied Measurement in Education, 21(4), 335-359.

Yin, Y., Tomita, M. K., \& Shavelson, R. J. (2008). Diagnosing and dealing with student misconceptions: floating and sinking. Science Scope, 31, 34-39.

Yin, Y., Tomita, M. K., \& Shavelson, R. J. (2014). Using formal embedded formative assessments aligned with a short-term learning progression to promote conceptual change andachievement in science. International Journal of Science Education, 36(4), 531-552. 


\section{Appendix}

\section{Buoyancy Test}

School Class

Name Student Number Gender $\square$ Boy $\square$ Girl

Instruction: Welcome to the Buoyancy Test. This test consists of an array of items which are related to the concept of buoyancy. You should try your best to complete it. Thank you very much!

1. When an object is put into a container full of water, it sinks. What is the direction of buoyancy during its sinking?
A. Vertically downward
C. Vertically upward
B. Downward but it is perpendicular to the container
D. No buoyancy

2. Draw the force diagrams for a ball in each of the following states and compare the forces of gravity and buoyancy.
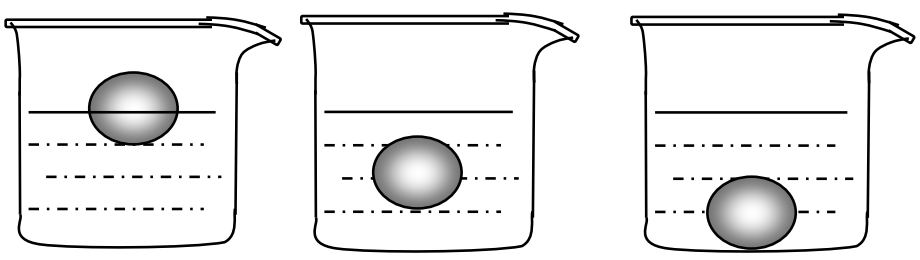

3. There are three objects all with a uniform mass distribution. Which of these objects has the greatest density?

\begin{tabular}{ccc} 
Object & Mass & Volume \\
\hline 1 & $\mathrm{~m}$ & $\mathrm{~V}$ \\
2 & $\mathrm{~m}$ & $2 \mathrm{~V}$ \\
3 & $2 \mathrm{~m}$ & $\mathrm{~V}$
\end{tabular}
A. Object 1
C. Object 3
B. Object 2
D. It cannot be determined

4. There are four same containers, of which the left parts are full of water and the right parts are empty (see the picture below). If we place four balls with the same volume into the left parts, water would flow into the right parts. According to the final states of these balls, which of the following choices represents the correct comparison among water volumes in the right parts? 

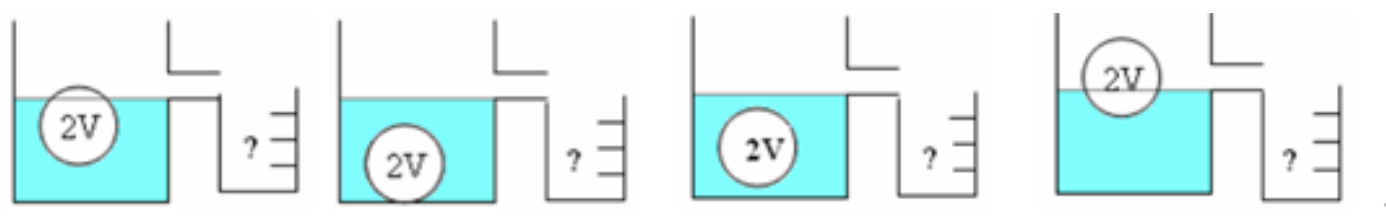
A. $\mathrm{V}_{1}=\mathrm{V}_{2}=\mathrm{V}_{3}=\mathrm{V}_{4}$
C. $V_{2}=V_{3}>V_{1}>V_{4}$
B. $V_{2}>V_{3}>V_{1}>V_{4}$
D. $V_{1}=V_{4}>V_{2}=V_{3}$

5. Block A sinks in container with water (see the picture below). As for the density of Block A, which of the following is most likely?
A. $0.3 \times 10^{3} \mathrm{~kg} / \mathrm{m}^{3}$
C. $0.8 \times 10^{3} \mathrm{~kg} / \mathrm{m}^{3}$
B. $0.5 \times 10^{3} \mathrm{~kg} / \mathrm{m}^{3}$
D. $1.1 \times 10^{3} \mathrm{~kg} / \mathrm{m}^{3}$

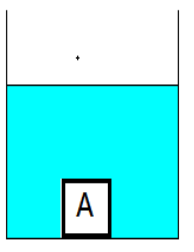

6. James puts one egg into a container with water, and this egg sinks to the bottom. If James wants to make this egg float, which of the following operations might be feasible?
A. Adding water
C. Adding alcohol
B. Adding salt
D. Evaporating water

7. If we put one ball into different liquids, it would float, hang, and sink in these liquids (see the picture below). As for its buoyancies, which of the following comparisons is right?

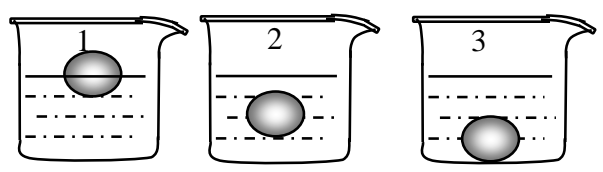
A. $F_{1}>F_{2}>F_{3}$
C. $\mathrm{F}_{1}>\mathrm{F}_{2}=\mathrm{F}_{3}$
B. $F_{1}=F_{2}>F_{3}$
D. $\mathrm{F}_{1}<\mathrm{F}_{2}<\mathrm{F}_{3}$

8. Object 1 , Object 2, Object 3, and Object 4 have different shapes, but they have the same mass. According to their states in water (see the picture below), which of these objects has the smallest buoyancy?
A. Object 1
C. Object 3
B. Object 2
D. Object 4

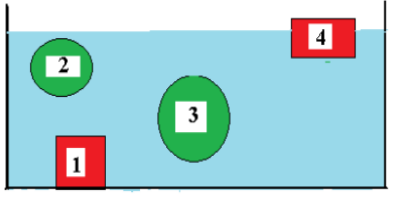

9. Block 1, Block 2, and Block 3 have the same mass, but they are made of different materials: copper, iron, and aluminum ( $\rho$ copper $>\rho$ iron $>\rho$ aluminum $)$. If we put these blocks into three same 
containers which are full of water, they would sink and the water would flow out. Which of these three circumstances has the greatest overflow water?
A. Copper
C. Aluminum
B. Iron
D. All are same

10. There is a big container which is full of water. If we put a ball whose mass is $0.3 \mathrm{~kg}$ in it, the mass of overflow water is $0.1 \mathrm{~kg}$. What's the magnitude of its buoyancy?
A. $1 \mathrm{~N}$
C. $3 \mathrm{~N}$
B. $2 \mathrm{~N}$
D. $4 \mathrm{~N}$

11. A block is made of wood with the density of $0.6 \times 10^{3} \mathrm{~kg} / \mathrm{m}^{3}$ and the mass of $0.3 \mathrm{~kg}$. If we place it in enough water, what's the magnitude of buoyancy?
A. $3 \mathrm{~N}$
C. $5 \mathrm{~N}$
B. $6 \mathrm{~N}$
D. It cannot be determined

12. A block is made of icon with the density of $7.8 \times 10^{3} \mathrm{~kg} / \mathrm{m}^{3}$ and the mass of $0.39 \mathrm{~kg}$. If we place it in enough water, what's the magnitude of buoyancy?
A. $7.8 \mathrm{~N}$
C. $3.9 \mathrm{~N}$
B. $0.5 \mathrm{~N}$
D. It cannot be determined

13. There is a wooden block floating in water. The volume of this block is $1 \times 10^{-3} \mathrm{~m}^{3}$, and the submerged volume accounts for $\frac{2}{5}$ of its whole volume. Which of the following options is right about the magnitude of buoyancy and its density?
A. $4 ; 0.4 \times 10^{3}$
C. $2 ; 0.2 \times 10^{3}$
B. $5 ; 0.5 \times 10^{3}$
D. It cannot be determined

14. Two identical blocks which are made of paraffin are placed into sufficient amounts of water and alcohol. What is the ratio of the blocks' submerged volumes in these liquids? ( $\rho$ paraffin $=0.9 \times 10^{3} \mathrm{~kg} / \mathrm{m}^{3}, \quad \rho$ alcohol $=0.8 \times 10^{3} \mathrm{~kg} / \mathrm{m}^{3}$ )
A. $9: 8$
C. $8: 9$
B. $1: 1$
D. It cannot be determined 